\title{
Self-reported automaticity and irrationality in spider phobia
}

Citation for published version (APA):

Maijer, B. N., Merckelbach, H. L. G. J., \& Muris, P. E. H. M. (2000). Self-reported automaticity and irrationality in spider phobia. Psychological Reports, 87, 395-405.

https://doi.org/10.2466/pr0.2000.87.2.395

Document status and date:

Published: 01/01/2000

DOI:

10.2466/pro.2000.87.2.395

Document Version:

Publisher's PDF, also known as Version of record

\section{Please check the document version of this publication:}

- A submitted manuscript is the version of the article upon submission and before peer-review. There can be important differences between the submitted version and the official published version of record.

People interested in the research are advised to contact the author for the final version of the publication, or visit the DOI to the publisher's website.

- The final author version and the galley proof are versions of the publication after peer review.

- The final published version features the final layout of the paper including the volume, issue and page numbers.

Link to publication

\footnotetext{
General rights rights.

- You may freely distribute the URL identifying the publication in the public portal. please follow below link for the End User Agreement:

www.umlib.nl/taverne-license

Take down policy

If you believe that this document breaches copyright please contact us at:

repository@maastrichtuniversity.nl

providing details and we will investigate your claim.
}

Copyright and moral rights for the publications made accessible in the public portal are retained by the authors and/or other copyright owners and it is a condition of accessing publications that users recognise and abide by the legal requirements associated with these

- Users may download and print one copy of any publication from the public portal for the purpose of private study or research.

- You may not further distribute the material or use it for any profit-making activity or commercial gain

If the publication is distributed under the terms of Article $25 \mathrm{fa}$ of the Dutch Copyright Act, indicated by the "Taverne" license above, 
Psychological Reports, 2000, 87, 395-405. Psychological Reports 2000

\title{
SELF-REPORTED AUTOMATICITY AND IRRATIONALITY IN SPIDER PHOBIA ${ }^{\prime}$
}

\author{
BIRGIT MAYER
}

Department of Social Sciences

The Open University of the Netherlands

HARALD MERCKELBACH AND PETER MURTS

Department of Experimental Psychology

Department of Medical, Clinical and Experimental Psychology

\section{Maastricht University}

Stmmary.-Spider phobic women $(n=39)$ and nonfearful controls $(n=41)$ completed a 20 -item questionnaire measuring the extent to which they experience their fear reactions to spiders as automatic and irrational, For the phobic sample, therapy outcone data were also collected. Results suggest that spider phobics tend to view their attitude to spiders as irrational and in this respect, they do not differ from control subjects. Furthermore, compared to control subjects, phobics more often perceive their responses to spiders as automatic, i.e., not under intentional control. Contrary to expectation, no robust correlation was found between automaticity and irrationality. Interestingly, automaticity was not related to treatment outcome, while irrationality to some extent predicted therapy outcome (i.e., the more phobics experienced their fear an irrational, the more they profited from exposure treatment).

Phobias are characterized by intense fear and avoidance of specific objects or situations. More precisely, the latest edition of the Diagnostic and Statistical Manual of Mental Disorders (DSM-IV; APA, 1994) stated that a person with a specific phobia recognizes that the fear is excessive and unjeasonable. DSM's portrayal of specific phobias as unreasonable or, in other words, irrational has become conventional wiscom among clinicians and researchers. For example, Page (1991) claimed that phobics acknowledge their fear to be unreasonable. Similarly, Soares and OHhman (1993) argued that rational arguments about the actual harmlessness of phobic stimuli are largely ineffective. In their view, this irrationality indicates that the phobic fear is not amenable to intentional conscious cognitive control. According to these authors, the irrational character of phobias would originate from certain preattentive, i.e., unconscious, mechanisms that would operate in phobias for biologically prepared stimuli such as spiders, snakes, and angry faces. More specifically, Soares and Öhman (1993; see also Öhman \& Soares,

'Address correspondence to Birgit Mayer, Department of Social Sciences, The Open University of The Nethedlands, P.O. Box 2960, 6401 DL Heerlen, The Netherlands or e-mail (birgit. mayer@ou.nl). 
1994) assumed that during the first milliseconds of a confrontation with the phobic object, preattentive processing of phobogenic information would immediately trigger physiological fear reactions, i.e., sympathic arousal. As a result, phobic persons would become fully aware of the phobic object at a point in time when physiological fear responses are already activated and this would explain why phobic persons experience their fear as irrational and uncontrollable.

In a series of experiments, Öhman and colleagues (Soares \& Öhman, 1993; Öhman \& Soares, 1994; Öhman, Esteves, \& Soares, 1995) monitored phobics' physiological reactions to subliminally presented phobic pictures, i.e., spiders, snakes, and found support for the idea that phobic responding is triggered by preattentive information processing. However, other authors (e.g., Globisch, Weike, \& Hamm, 1996; Mayer, Merckelbach, de Jong, \& Leeuw, 1999) were unable to replicate these effects. Apart from that, surprisingly few studies have addressed the issue of whether phobics actually experience their fear as an automatic, involuntary response. If a phobic response is, indeed, activated before conscious reflection comes into play, one would expect that phobic persons describe the phenomenology of their fear in terms of an automatic response that is not under intentional control.

As to the irrational character that the DSM-IV ascribes to phobias, it remains to be seen whether phobic persons really experience their fear in this way. For example, Arntz, Lavy, Van den Berg, and van Rijsoort (1993) noted that persons with spider phobias have a range of negative cognitions about spiders. These authors found that such people strongly endorse all sorts of negative ideas about spiders, e.g., "The spider will attack me," and about their reactions during an encounter with spiders, c.g., "I will die because of fear." Similar results were obtained by Thorpe and Salkovskis (1995), who found that phobic persons strongly believe that harm will befall them if confronted with a spider, e.g., "I would make a fool of myself" or "I would feel faint." Thus, the findings of Arntz, et al. (1993) and Thorpe and Salkovskis (1995) suggest that from the phobic patient's point of view, it is rational to react with intense fear to the phobic object. In other words, these findings refute the common notion of phobic persons readily admitting the irrationality of their fear.

The present study was a first attempt to clarify to what extent phobic persons experience their fear as automatic, i.e., involuntary, and irrational and whether there is a connection between these two features. To this end, the Automaticity Irrationality Questionnaire was employed to assess and evaluate in a systematic fashion the phenomena of automaticity and irrationality in phobic fear. Spider phobic persons and normal controls completed this scale and group differences in automaticity and irrationality of spider fear. were tested. Furthermore, the association between automaticity and irratio- 
nality was analysed in more detail. If, as Öhman and Soares (1994) claim, automaticity underlies irrationality, one would expect a robust connection between these two features. Finally, we examined whether irrationality and automaticity are predictors of therapy outcome. In their study of exposure effects in spider phobic, Öst, Salkovslkis, and Hellström (1991) concluded that the most important factor in one-session treatment is making explicit the patients' catastrophic thoughts concerning the phobic situation. To the extent that exposure therapy is effective because it corrects a set of elaborated and articulated misconceptions that phobic persons have (see also, Foa \& Kozak, 1986), one would expect that phobic persons who experience their fear as highly automatic or irrational (in the sense of acknowledging that spiders are harmless) will benefit less from this treatment. On the other hand, there are some indications that phobic persons who are convinced of the rationality of their fear profit less from therapy (e.g., Thorpe \& Salkovskis, 1995).

T'o summarize, then, the present study investigated automaticity and irrationality in spider phobia. More specifically, two hypotheses were investigated. (1) Spider phobic patients report higher scores on automaticity and irrationality than normal controls. (2) Self-reported automaticity and irrationality are positively intercorrelated. An additional purpose was to examine the effects of self-reported automaticity and irrationality on outcome of exposure therapy.

\section{Participanls}

\section{METHOD}

Participants were 39 spider phobic women who applied for treatment at the University Spider Phobic Project of Manstricht University, and 41 control women. Phobic participants were only included if they met the full DSM-IV (APA, 1994) criteria for specific phobia (animal type) including the functional impaiment criterion. Diagnoses were made by a trained psychologist. The phobic women did not suffer from significant other psychiatric disorders. Mean age of the phobic group was 31.5 yr. $(S D=8.8)$. Control women were selected from a large pool of individuals recruited by advertisements in a local newspaper. Control women did not exhibit fear of spiders and were only included when they also did not suffer from other mental disorders. They received a financial compensation for participation. Mean age of the control group was $31.2 \mathrm{yr},(S D=8.1)$. Groups were matched as much as possible for socioeconomic background (based on the occupational status of the participants).

Arsessment

The Fear of Spiclers Questionnaire (Szymanski \& O'Donohue, 1995; Muris \& Merckelbach, 1996) has 18 items that refer to a restricted time period (c.g., "If I encounter a spider now, I would have images of it trying to 
get me"). Items are evaluated on 7-point Likert scales (1: strongly disagree and 7: strongly agree). Accordingly, scores range between 18 and 126, with higher scores reflecting greater fear of spiders.

The Spider Phobia Beliefs Questionnaire (Arntz, et al., 1993) comprises two scales that assess the strength of negative beliefs about spiders, i.e., Beliefs About Spiders (e.g., "The spider will attack me") and about reactions of the individual during confrontation with a spider, i.e., Beliefs About Self (e.g., "I will lose control"). Items of both subscales range from 0 : absence of negative beliefs and 100: very strong beliefs.

Both self-report questionnaires of spider phobia have been reported to be highly reliable and satisfactory in terms of concurrent and predictive validity (Arntz, et al., 1993; Szymanski \& O'Donohue, 1995; Muris \& Merckelbach, 1996).

A behavioral avoidance test was used to measure actual avoidance of spiders. During this test, participants had to approach a live spider in a stepwise manner. Scores range from 0: spider at $3 \mathrm{~m}$ distance and 8: spider on the hand. Thus, high scores reflect better performance, i.e., less fear of spiders.

The Automaticity Irrationality Questionnaire was developed for the purpose of the present study. The original questionnaire consisted of 23 items referring to automaticity or irrationality involved in responses to spiders. Each item was scored on a 5-point Likert scale (1: strongly disagree and 5: strongly agree). High scores on automaticity items indicate that respondents feel that they have little intentional control over their reactions to spiders. High scores on irrationality items imply that respondents readily acknowledge the harmlessness of spiders, while low scores indicate that respondents are not sure about this.

Exploratory factor analysis of the Automaticity Irrationality Questionnaire (principal components with varimax rotation) yielded two factors, i.e., automaticity and irrationality, but also showed that three irrationality itens, i.e., "I can imagine that many people dare to touch a spider," "I can imagine that fear of spiders passes off after a while," and "I think of spiders more as disgusting than as dangerous," did not load convincingly on their intended factor, i.e., $.27, .19$, and -19 , respectively. These items were removed from the questionnaire, leaving a total of 20 items, i.e., 13 automaticity items and 7 irrationality items. Factor analysis of this final version confirmed the two-factor structure. Table 1 below shows various items and their loadings on the two factors after rotation. As can be seen, automaticity items loaded convincingly on the first factor (eigenvalue 10.36, explained variance $51.8 \%$ ), whereas irrationality items loaded clearly on the second factor (eigenvalue 2.66 , explained variance $13.3 \%$ ). Cronbach alphas for the automaticity and irrationality scales in the total sample were .97 and .70 , respective- 
ly. For the phobic sample, these coefficients were .68 and .77 , respectively, For the controls, coefficients were .82 and .69 , respectively.

Procedure

All participants came to the laboratory individually. Before treatment, spider phobic women filled out the Automaticity Irrationality Questionnaire and questionnaires about spider fear and beliefs. In addition, they underwent the behavioral avoidance test. Treatment was carried out in a private room at the university and consisted of $3 \mathrm{hr}$, exposure in vivo (Öst, 1989). Briefly, this treatment consists of one session that contains elements such as hierarchically structured confrontation with spiders, modeling by the therapist, and encouragement to interact with spiders. After treatment, spider phobic persons filled out the questionnaires about fear of spiders and beliefs and underwent the behavioral avoidance test again. Control participants only completed the Automaticity Irrationality Questionnaire, the spider fear questionnaire and carried out the behavioral avoidance test once.

\section{Statistical Analysis}

The Statistical Package for Social Sciences (SPSS) was used for computing descriptive statistics, correlations, and carrying out (two-tailed) $t$ tests and factor analysis. In cases where multiple $t$ tests were conducted and several correlations were computed, Bonferroni adjustments were applied.

\section{Results}

\section{Pbobic us Control Groups}

As expected, the phobic group had higher scores on the spider fear questionnaire than the control group, means being $98.0(S D=13.6)$ and 1.5 $(S D=3.2)$, respectively $\left[t_{+2.1}\right.$ (adjusted $\left.\left.d f\right)=43.1, p<.001\right]$. Phobic persons also performed worse on the behavional test compared to the control group, means being $3.6(S D=1.9)$ and $7.7(S D=0.8)$, respectively $\left[l_{4.2 .2}\right.$ (adjusted $d f)=12.7, p<.001]$. In passing, it should be noted that the phobic groups' scores on the spider fear questionnaire and the behavioral avoidance test were quite comparable to those reported by Muris and Merckelbach (1996) for their sample of spider phobic persons.

Furthermore, the two groups differed in terms of their mean scores on the automaticity scale, means being $55.0(S D=5.3)$ and $20.2(S D=6.9)$, for the phobic and control groups, respectively $\left(t_{7 \mathrm{x}}=25.3, p<.001\right)$. Post boc $t$ tests indicated that significant differences between groups were present on all automaticity items (see Table 1). In other words, the phobic group perceived their responses to spiders as more automatic in nature than did control subjects.

A $t$ test yielded no significant difference between phobic and control groups with regard to the Irrationality scale, means being $24.6(S D=5.7)$ and 
B. MAYER, ET AL.

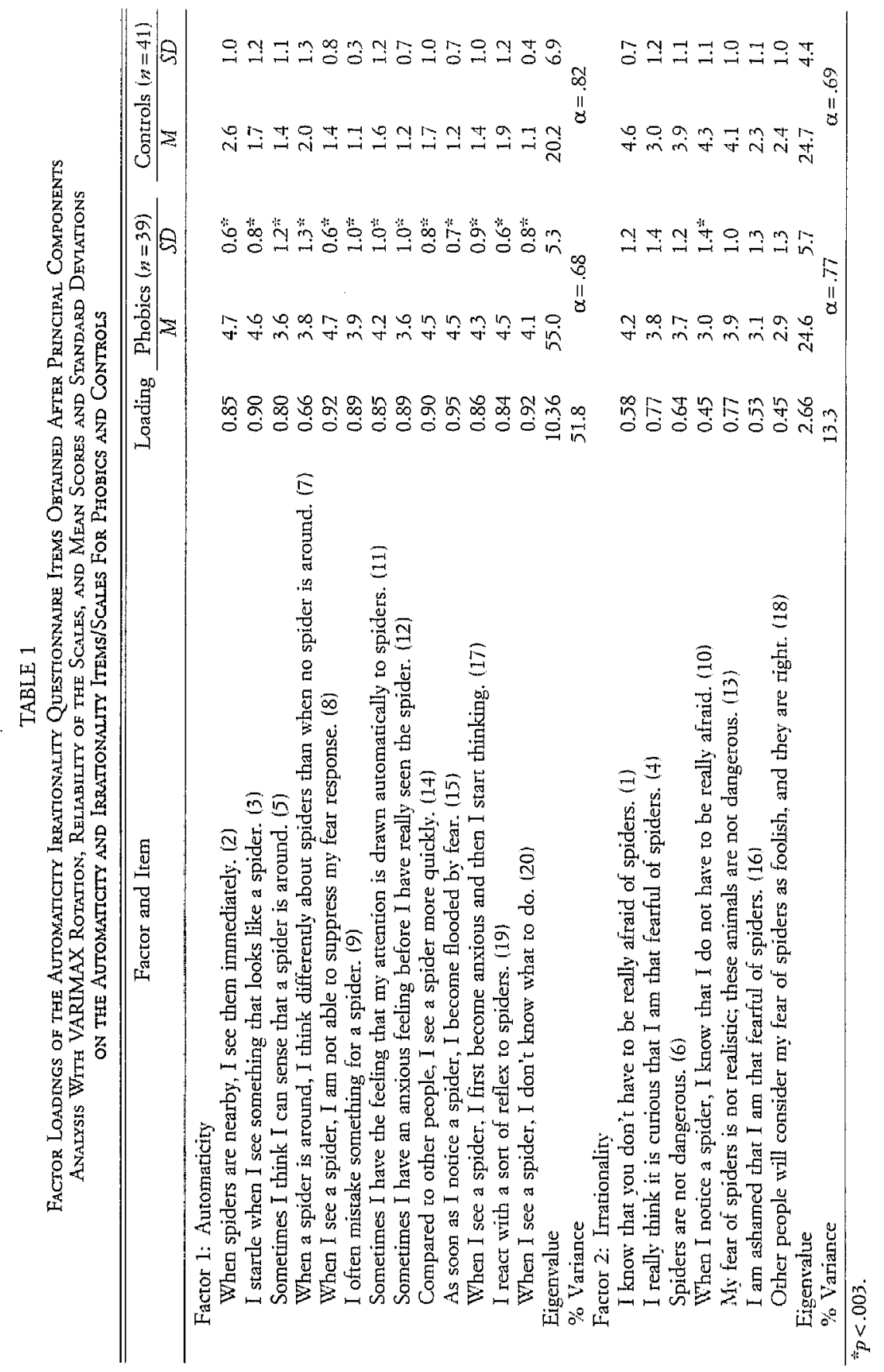


$24.7(S D=4.4)$, respectively $\left(t_{74}<1.0\right)$. Thus, the former did not have a stronger belief in the dangerousness of spiders than the latter.

Correlations Between Automaticity and Irrationality

Pearson product-moment correlations were computed between automaticity and irrationality. In line with the two-factor solution suggested by the factor analysis, scores for automaticity and irrationality were not correlated $(r=-.09$, ns $)$ in the total sample, i.e., phobic and control subjects. For the nonfearful control group, there was a small, negative correlation between automaticity and irrationality $(r=-.35, p<.05)$. That is, the more control subjects experienced their 'fear' as automatic, i.e., involuntary, the less they tended to depict spiders as harmless animals. For the phobic group, no such an association between automaticity and irrationality was evident ( $r=-.17$, ns).

Correlations Between Automaticity and Irrationality and Severity of Fear of Spiders

Pearson product-moment correlations were computed between automaticity and irrationality scores on the one hand, and measures of fear: of spiders on the other hand. This was done for the total sample, and also for phobic and nonphobic groups separately. For the total sample, automaticity scores were significantly associated with spider fear $(r=.94, p<.001)$ and avoidance behavior $(r=-.78, p<.001)$. There were no significant correlations between irrationality scores and spider fear or avoidance behavior ( $r$ s were -.08 and .14 , respectively).

TABLE 2

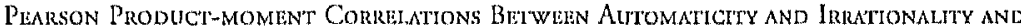
Pre- and Post'triatmente Spider Phobia Mansures For Phobic Group $(n=39)$

\begin{tabular}{lcc}
\hline & Automaticity & Trrationality \\
\hline Pretrentment & .19 & $-.47 \%$ \\
Spider fear & .23 & $-.45+$ \\
Beliefs about spiders & .15 & -.21 \\
Beliefs about self & .17 & .23 \\
Avoidance behavior & & \\
Posttreatment & -.08 & -.18 \\
Spider fear & .04 & $-.41^{*}$ \\
Belicfs about spiders & -.03 & -.19 \\
Beliefs about seif & -.05 & $.41^{*}$ \\
Avoidance behavior & &
\end{tabular}

$t_{p}<.05 .+p<.006$

In the control group, automaticity scores correlated with fear of spiders $(r=.43, p<.005)$. There was no significant correlation between automaticity and avoidance behavior $(r=-.28$, ns). Moreover, ilrationality was not associated with subjective and behavioral indices of fear of spiders. 
In the phobic group, no significant associations between automaticity and measures of spider phobia were observed. Irrationality scores, however, were negatively correlated with fear of spiders and beliefs about spiders (see upper part of Table 2). That is, for phobics, a tendency to portray spiders as harmless animals, i.e., high irrationality scores, was accompanied by relatively low fear of spiders and a relatively weaker tendency to endorse negative beliefs about spiders.

\section{Automaticity, Irrationality and Therapy Outcome}

Correlations between automaticity and irrationality scores, and therapy outcome measures for phobic subjects are shown in the lower rows of Table 2. As can be seen, automaticity scores did not correlate with any of the outcome measures. In contrast, irrationality was associated with posttreatment beliefs about spiders and posttreatment avoidance behavior. When pretreatment scores were partialled out, only the correlation of irrationality scores with posttreatment avoidance behavior remained marginally significant (partial $r=.34, p<.05$ ). The direction of this correlation indicates that the more phobic persons describe spiders as harmless animals, the more a subsequent exposure session will reduce their avoidance behavior. Altogether, these results suggest that automaticity is not related to treatment outcome, while irrationality to some extent predicts therapy outcome as measured at the behavioral level.

\section{Discussion}

The DSM-IV assumes that individuals with specific phobias acknowledge that their fears are irrational. The present study examined whether this assumption is correct. In addition, an attempt was made to determine whether at the phenomenological level, the alleged irrationality of phobic fear is a function of automaticity, as Öhman and Soares (1994) claimed. 'The main results of the present study can be summarized as follows. To begin with, in line with the DSM-IV description, spider phobic subjects felt that their fear reactions to spiders were not justified by the dangerousness of spiders. In other words, they tended to view their reactions to spiders as irrational, and they did not differ in this respect from normal control persons: both groups tended to view fear: of spiders as irrational. While these findings support the DSM-IV position, they are difficult to reconcile with the results reported by Arntz, et al. (1993) and Thorpe and Salkovskis (1995). These researchers noted that phobic persons strongly believe when confronted with spiders that harm will befall them. Clearly, endorsing such a belief implies that feal of spiders is rational. The discrepancy between the current findingss and the results of Arntz, et al. (1993) and Thorpe and Salkovskis (1995) might be related to the fact that the irrationality items of the Automaticity Irrationality Questionnaire tap global ideas and attitudes about spiders, while measures 
such as the Spider Phobia Beliefs Questionnaire ask for detailed and idiosyncratic cognitions about spiders and the fear reactions they elicit. Possibly, a global measure of the sort used in the current study is less sensitive to idiosyncratic expectations of danger that some phobic persons might have.

A related issue is that two of the seven irrationality items used in the present study evaluate the irrationality of fear of spiders from the point of view of other people, i.e., public notions of irrationality. Yet, it is possible that at least some spider phobics believe that confrontation with a spider will have catastrophic results (internal irrationality) and at the same time acknowledge that other people will not share this view (external irrationality). The present study also found that spider phobics' irrationality scores correlate negatively with their scores on the Spider Phobia Beliefs Questionnaire. Thus, low irrationality scores are accompanied by strong negative beliefs about spiders. Apparently, as a group, spider phobics do not differ from nonfearful controls in qualifying fear of spiders as irrational, possibly because most phobics are able to adopt public notions of irrationality. Within the phobic group, however, there is at subgroup of phobics who strongly believe various negative ideas about spiders and who are less willing to define their fear of spiders as irrational or unreasonable.

A second finding of the current study that deserves some comment is that phobic subjects experienced their reactions to spiders as more automatic, i.e., more involuntary, than did control subjects. This is, of course, in line with the position of Öhman and Soares (1994), as is the finding that higher scores for automaticity were positively related to fear of spiders and avoidance. In the present study, however, no substantial correlation was found between automaticity and irrationality. Thus, at least at the phenomenological level, there is no straightforward connection between the self-reported absence of intentional control over fear responses and the tendency to view this fear as unreasonable. This finding can be taken as an argument against Öhman and Soares, who claimed that the irrational character of phobias is a function of the automaticity (involuntariness) of phobic responses. One could counter that their automaticity hypothesis pertains to physiological processes rather than phobic subjects' scif-reports. On the other hand, automaticity and irrationality refer to meta-cognitive judgements, and this makes the present study's reliance on self-report measures legitimate.

A third finding of the present investigation is that, in contrast to our expectations, pretreatment automaticity ratings were not related to therapy outcone. It was anticipated that for a phobic person who responds highly automatically to the feared object, it is more difficult to profit from the corrective information offered by exposure in vivo. While this was not borne out by the data, our failure to find a connection between automaticity and therapy outcome might be due to a restriction-of-range problem. That is, all 
phobic subjects reported high automaticity, and there was relatively little variance within this group $(M=55.0 ; S D=5.3$; range $0-65)$. In line with previous findings of Thorpe and Salkovskis (1995), the present study showed a connection between itrationality and posttreatment avoidance of spiders such that the more the phobic women were convinced of the dangerousness of spiders, i.e., the rationality of their fear, the less they profited from behavior therapy. This implies that those phobic women who endorse strong danger expectations about spiders respond less to therapy, a finding that underlies the idea that it might be valuable to include cognitive elements in exposure treatment (e.g., Foa \& Kozak, 1986; Öst, Salkovskis, \& Heliström, 1991).

In the present study, automaticity and irrationality were measured by means of a newly developed questionnaire. Although it was not our aim to develop a new clinical tool, it should be acknowledged that the psychometrics of the scale were based on a relatively small sample of phobic and control subjects. Hence, the present findings should be interpreted with some caution. Nevertheless, the findings described here support the idea that, on the whole, spider phobias are experienced as irrational and automatic in nature (Öhman \& Soares, 1994). They do not show, however, that automaticity and irrationality are related to each other, as implicated by Öhman and Soares' proposal. Furthermore, automaticity was not related to trentment outcome, whereas irrationality to some extent predicted therapy outcone. More specifically, phobic women who were more convinced of the dangerousness of spiclers profited less from exposure in vivo. Cleatly, the role that 'rational' and 'irrational' beliefs play in exposure treatment deserves further study.

\section{RIITERENCIS}

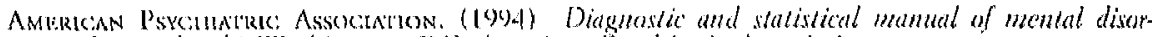
ders. (4the el.) Washington, D(:) American Psychiatric Association.

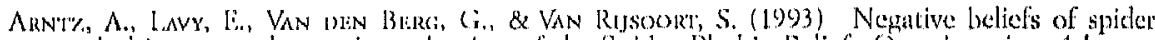
phoblics: a psychemetric cvaluation of the Spicter Phobial Beliefs Ouestionnaire. Aduances in Behowiour Researd and Therthy, 15, 257.277.

IOOA, L. B., \& Korak, M. J. (1986) Limotional processing of feall: expostre to cotrective information. Psycholongial Bulletin, 99, 20-35.

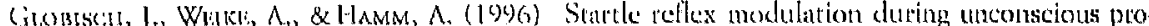
cessing of fear-evolking slicks in animal ploblics. Prychophysiology, 33, S4 L. [Abstract]

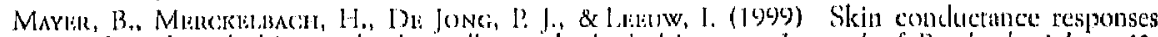

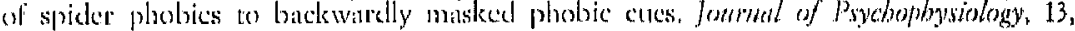
$152-159$

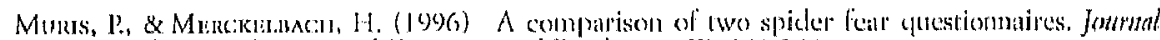

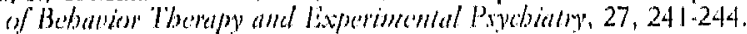

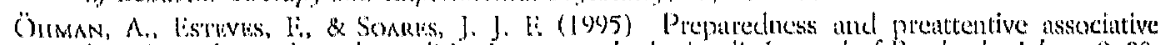

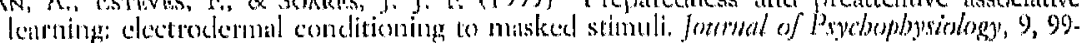
108.

Öhman, A. \& Sodrks, J. J. 1: (1994) "Unconscious procesises": phobic responses to masked stimuli. Fournal of Ahmormal Psychology, 103, 231-240.

Ösr, 1.-(i. (1989) Onc-session trealment for specific phobias. Bchatiour Rescarch and Therapy, $27,1-7$. 
Ösr, L-G., SAlkovsiris, I? M., \& Hellström, K. (1991) One-session therapist directed exposure vs self-exposure in the treatment of spider phobia. Behavior Therapy, 22, 407-422.

PAGr, A. C. (1991) Simple phobias, International Remiew of Psychintry, 3, 175-187.

SOAres, J. J. F, \& Öhman, A. (1993) Backward masking and skin conductance responses after conditioning to nonfeared but fear-relevant stimuli in farful subjects. Psycbopbysiology, $30,460-466$.

Szymanski, J., \& O'Dononue, W. (1995) Fear of Spider's Questionnaire. Journal of Bebaviou Therapy and Experimental Psycbiatry, 26, 31-34.

Thorpe, S. J., \& Salkovskis, P. M. (1995) Phobic beliefs: do cognitive factors play a role in specific phobias? Behaviour Researcb and Therapy, 33, 805-816.

Accepted August 1, 2000. 